\title{
Methadone Gastrobezoar in a Psychiatric Patient Presented in Coma
}

\author{
Alexandra Gavala1, Despoina Manou², Vasiliki Psalida1, Maria Nystatzaki ${ }^{3}$, Christos Mavrogiannis ${ }^{2,4}$, George Alevizopoulos ${ }^{3,4}$, Pavlos Myrianthefs ${ }^{1,4}$ \\ ${ }^{1}$ Department of Intensive Care Unit, Kaliftaki, 14564, Nea Kifissia, Departments of ${ }^{2}$ Gastrenterology and ${ }^{3 P}$ sychiatry at “Agioi Anargyroi” General Hospital, Kaliftaki, \\ 14564, Nea Kifissia, ${ }^{4}$ Faculty of Nursing, School of Health Sciences, National and Kapodistrian University of Athens, Greece
}

\section{Abstract}

A 43-year-old psychiatric patient was transferred in coma and hypercapnic respiratory failure at the emergency department. He was intubated for airway protection and transferred to the Intensive Care Unit (ICU). Abdominal X-ray revealed a radiopaque mass; a pharmacobezoar was suspected and confirmed by gastroscopy; one large in the stomach fundus and a smaller one in the pylorus. Gastric lavage through the gastroscope and administration of gastro-kinetic drugs and laxatives were able to dilute the bezoars. Tablets retrieved from the stomach identified as methadone and toxicological tests of the gastric fluid confirmed the presence of methadone as the only organic chemical compound. The patient was extubated on the $7^{\text {th }}$ day and released from the ICU on the $10^{\text {th }}$ day under psychiatric consultation having normal vital signs. Methadone gastric bezoar may lead to persistent intoxication, respiratory failure, and coma requiring ICU care. Diagnosis may be difficult and a high index of suspicion is needed.

Keywords: Acute care, gastroscopy, intoxication, methadone, pharmacobezoar

\section{INTRODUCTION}

Drug gastrobezoars are rare complications but may cause significant medical problems. ${ }^{[1]}$ Methadone gastrobezoar has never been previously reported in cases of acute intoxication. ${ }^{[2]}$

\section{Case Report}

A 43-year-old man was transferred at the emergency department (ED) in coma (Glasgow coma scale: 3) and pinpoint pupils having blood pressure of 100/60 $\mathrm{mmHg}$, $\mathrm{SpO}_{2}$ of $88 \%$ on air, heart rate of $90 / \mathrm{min}$, normal ECG, temperature of $36.5^{\circ} \mathrm{C}$, respiratory rate of $7 / \mathrm{min}$, and sparse bowel sounds. He responded to intravenous (i.v.) flumazenil and naloxone administration improving his consciousness reporting previous use of fentanyl and trihexyphenidyl p.o. He was finally intubated having coma and hypercapnic respiratory failure $\left(\mathrm{PaO}_{2}=87 \mathrm{mmHg}, \mathrm{PaCO}_{2}=61 \mathrm{mmHg}\right.$, and $\left.\mathrm{pH}=7.28\right)$. A brain computed tomography (CT) scanning was negative for brain pathology.

He had hepatitis $\mathrm{C}$ virus infection, was a heavy smoker and drug abused since he was 16 years old (sisa, opioids, cannabis, and amphetamines), and was treated for drug addiction using

\begin{tabular}{|l|l|}
\hline \multicolumn{3}{|c|}{ Access this article online } \\
\hline Quick Response Code: & Website: \\
& www.ijccm.org \\
\hline
\end{tabular}

methadone (pills of $20 \mathrm{mg} /$ day) for the last 10 years. He was also managed for depression and schizophrenia (currently on olanzapine, alprazolam). It was also reported a double attempt for suicide during the last 12 months using quetiapine fumarate.

On Intensive Care Unit (ICU) admission, he was afebrile and hemodynamically stable. A right jugular central venous catheter and a right radial arterial line were placed. A chest X-ray was normal. He was given i.v. naloxone infusion (maximum daily dose of $10 \mathrm{mg}$ ). Furthermore, he was given gastric stress ulcer prevention (omeprazole $40 \mathrm{mg}$ i.v.), deep vein thrombosis prophylaxis (fondaparinux $2.5 \mathrm{mg} \mathrm{sc}$ ), activated charcoal, lactulose $(20 \mathrm{ml}$ tid $)$, diatrizoate meglumine/diatrizoate sodium $66 \mathrm{~g}+10 \mathrm{~g} / 100 \mathrm{ml}$ (50 ml once) per-nasogastric (NG) tube, and ampicillin-sulbactam for suspected aspiration. He received increased fluid turnover using normal saline $(0.9 \%)$

\section{Address for correspondence: Prof. Pavlos Myrianthefs, Sokratous 4A, Kifissia, Athens 14561, Greece. E-mail: pmiriant@nurs.uoa.gr}

This is an open access article distributed under the terms of the Creative Commons Attribution-NonCommercial-ShareAlike 3.0 License, which allows others to remix, tweak, and build upon the work non-commercially, as long as the author is credited and the new creations are licensed under the identical terms.

For reprints contact: reprints@medknow.com

How to cite this article: Gavala A, Manou D, Psalida V, Nystatzaki M, Mavrogiannis C, Alevizopoulos G, et al. Methadone gastrobezoar in a psychiatric patient presented in coma. Indian J Crit Care Med 2017;21:796-8. 
i.v. and furosemide on demand. Abnormal laboratory findings included platelets $(\mathrm{PLTs})=87.000 / \mathrm{mm}^{3}$, and slightly increased gamma-glutamyltransferase $=92 \mathrm{U} / \mathrm{L}$, serum glutamic pyruvic transaminase (alanine aminotransferase) $=71 \mathrm{U} / \mathrm{L}$, creatine phosphokinase $=683 \mathrm{U} / \mathrm{L}$, amylase $144 \mathrm{U} / \mathrm{L}$, and $\mathrm{C}$-reactive protein $=19 \mathrm{mg} / \mathrm{L}$. A urine point of being test was positive for methadone and midazolam. Further toxicological tests using qualitative tests in urine samples revealed methadone, alprazolam, olanzapine, 11 -nor- $\Delta 9$ THC-9 carbolic acid (cannabis), and amphetamine derivatives.

Next morning, diatrizoate meglumine/diatrizoate sodium was administered $(50 \mathrm{ml})$ and a plain abdominal X-ray was ordered showing a rounded opacity in the stomach [Figure 1]. Emergency gastroscopy showed gastric erosions and a huge $(5 \mathrm{~cm} \times 7 \mathrm{~cm})$ gray bezoar which was immobile and was not able to dilute with water [Figure 2a-c]. A second, smaller, bezoar was identified obstructing the outlet of the pylorus but was able to wash and remove to the stomach antrum [Figure 2d]. After washing the bezoars, white-colored tablets were found. Gastric fluid samples and tablets toxicological examinations revealed methadone as the only organic chemical compound.

Continuous gastric lavage was applied using N/S $0.9 \%$ via a double lumen NG tube with a flow of $100 \mathrm{ml} / \mathrm{h}$. Additional i.v. gastro-kinetic drugs were started (metoclopramide $10 \mathrm{mg}$ tid and erythromycin $250 \mathrm{mg}$ qds i.v.) along with laxatives (lactulose $20 \mathrm{ml}$ tid) per-NG tube. Next day, gastroscopy showed a significant decrease of the huge bezoar while the smaller one disappeared. Further endoscopy was ruled out due to the severe erosions found in the esophagus and the pylorus. Continuous gastric lavage was applied until the $5^{\text {th }}$ day. Total parenteral nutrition was also started until cleaning of the bowel from drug residues. Bowel sounds were present and daily stools were reported indicating bowel decontamination while sequential abdominal X-rays were normal. His laboratory examinations including PLTs were normalized. The next days, the patient was significantly

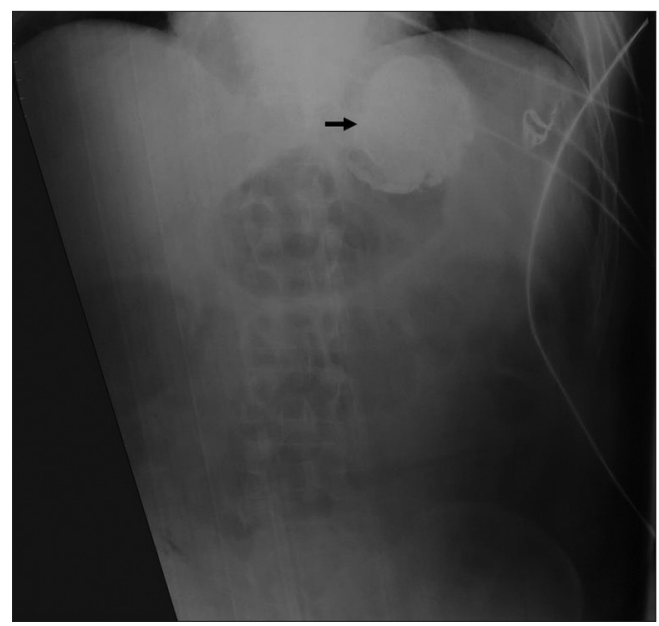

Figure 1: Abdominal plain X-ray showing rounded radiopaque opacity in the stomach indicating the presence of a gastric bezoar improved and was extubated on the $7^{\text {th }}$ day. Oral feeding was started on the $9^{\text {th }}$ day to ensure that all drug residues were discarded and that the patient was able to swallow.

The patient was discharged from the ICU on the $10^{\text {th }}$ day after psychiatric consultation, monitoring, and supervision to the hospital ward. A follow-up gastroscopy 2 months after ICU discharge revealed nothing except several mild gastric erosions. He reported that he was taking not only his regular antipsychotic drugs but also additional methadone in the form of tablets for satisfaction.

\section{Discussion}

The word "bezoar" is derived from Arabic "bazahr" or "badzehr," which means antidote or counter-poison to poisons.${ }^{[3]}$ Currently, it refers to a potentially serious medical problem resulting from the accumulation of ingested inedible foreign material. ${ }^{[1]}$

The pathogenesis involves alterations in the production of acid, pepsin, and mucus and impairments in the grinding mechanism of the stomach. ${ }^{[4]}$ Major risk factors include altered gastric anatomy, compromised gastric motility, diabetes mellitus, and gastroparesis. ${ }^{[1,3]}$ Other predisposing factors include poor mastication, excessive intake of fiber, cystic fibrosis, dehydration, co-ingested medications, and psychiatric illness. ${ }^{[1,5]}$

Bezoars are defined based on their consistency: diospyrobezoars; trichobezoars; phytobezoars; lactobezoars; and pharmacobezoars or medication bezoars. ${ }^{[6]}$ Pharmacobezoars are mostly tablets or capsules, suspensions or semiliquid drugs, found following overdose of sustained-release medications or due to insoluble drug delivery vehicles coalescing in the gastrointestinal (GI) tract. ${ }^{[2,7-9]}$ Pharmacobezoars can present with gastric outlet obstruction and symptoms due to the pharmacologic properties of their active ingredients
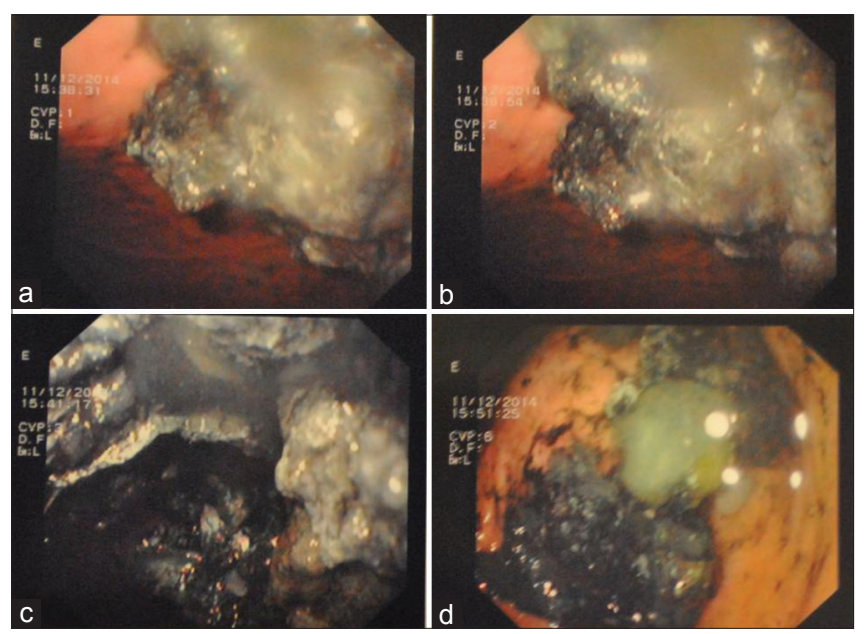

Figure 2: (a) Gastric fundus showing a large gray (due to activated charcoal) colored pharmacobezoar. (b and c) Gastric body showing a large gray-colored gastrobezoar. (d) Pyloric outlet obstruction with a smaller also gray-colored pharmacobezoar 
within the bezoar causing persistent or recurrent drug intoxication..$^{[2,5,8]}$ Diagnosis is suspected by medical history, clinical examination, and the course of the clinical condition of the patient.

Management strategies depend on location, type, and cause of the bezoar and include lavage or chemical dissolution, endoscopy, fragmentation, and/or retrieval while surgical treatment remains the last choice when conservative measures have failed. ${ }^{[1]}$ The treatment of pharmacobezoars depends on the pharmaceutical agent, size, location, and the patient's clinical status and can range from gastric decontamination (gastric lavage) to dissolution therapy, repeated administration of activated charcoal, bowel irrigation, endoscopic retrieval, or surgical removal for patients with bowel obstruction or other complications. ${ }^{[5]}$ Close clinical observation and monitoring of the plasma drug concentrations are also recommended. ${ }^{[1,3]}$ Gastroscopic removal, fragmentation, and extraction of a pharmacobezoar may cause complications including hemorrhage; hence, the procedure is recommended only if an experienced endoscopist is available. ${ }^{[9,10]}$

In our case, dehydration, concurrent use of methadone, trihexyphenidyl, olanzapine, and alprazolam with possible anti-cholinergic synergistic gastroparetic effect and the underlying psychiatric illness could be related to gastroparesis and methadone gastrobezoar formation. His medical history of psychosis, drug addiction, and the double attempt for suicide were also valuable hints for his coma. Furthermore, he had pinpoint pupils which are compatible to methadone overdose. Considering the pharmacodynamics, methadone itself has a long duration of action and prolonged elimination that alone could explain his severe and prolonged intoxication. In cases like ours, diagnosis can be suspected only by ordering imaging studies (X-ray, ultrasound, or CT scan) and confirmed by endoscopy as a method of choice. Intubation, mechanical ventilation, and ICU care were mandatory due to the development of hypercapnic respiratory failure and coma predisposing for aspiration. Gastric decontamination, dissolution therapy, bowel irrigation, and endoscopy were applied to remove the bezoar. ${ }^{[1,3,9]}$ Endoscopy was crucial for the documentation of the bezoar and helped wash and lavage the stomach but was not able to remove the bezoar. It seems that continuous gastric lavage had the most important role in the dissolution of the bezoar. Gastro-kinetic drugs, laxatives, and diatrizoate meglumine/diatrizoate sodium probably played an additional role in the emptying the stomach and avoid surgical complications such as GI obstruction.

In our case, the pharmacobezoar was discovered after drug overdose and the development of coma. This was confirmed by urine and gastric fluid, methadone, methamphetamine, alprazolam, and olanzapine identification and by direct observation of the bezoars through the endoscope. However, the only chemical substance identified in the gastric fluid was methadone. Thus, despite the patient used all identified substances as his regular antipsychotic medications, the composition of the bezoar was methadone only. However, the role of other potential ingestants and the excipients of the formulation and other drug formulations specific to the agents found on urine toxicology assessment that could contribute to bezoar formation cannot be definitely excluded.

\section{ConcLusion}

Diagnosis of pharmacogastrobezoars requires a high index of suspicion and can be easily made by imaging studies and endoscopy. This is especially meaningful in cases of drug intoxication requiring ICU admission or severe, prolonged or recurrent intoxication for prompt and proper management. In our patient, dissolution through endoscopy and continuous gastric lavage was effective. To our knowledge, this is the first case in the literature describing a psychiatric patient having a methadone gastrobezoar intoxication requiring ICU care with favorable outcome.

\section{Declaration of patient consent}

The authors certify that they have obtained all appropriate patient consent forms. In the form the patient(s) has/have given his/her/their consent for his/her/their images and other clinical information to be reported in the journal. The patients understand that their names and initials will not be published and due efforts will be made to conceal their identity, but anonymity cannot be guaranteed.

\section{Acknowledgments}

We would like to thank Athens University, Division of Forensic Medicine - Toxicology for toxicological examinations and results.

\section{Financial support and sponsorship}

Nil.

\section{Conflicts of interest}

There are no conflicts of interest.

\section{RefEREnCeS}

1. Eng K, Kay M. Gastrointestinal bezoars: History and current treatment paradigms. Gastroenterol Hepatol (N Y) 2012;8:776-8.

2. Simpson SE. Pharmacobezoars described and demystified. Clin Toxicol (Phila) 2011;49:72-89.

3. Williams RS. The fascinating history of bezoars. Med J Aust 1986;145:613-4

4. Lee J. Bezoars and foreign bodies of the stomach. Gastrointest Endosc Clin N Am 1996;6:605-19.

5. Taylor JR, Streetman DS, Castle SS. Medication bezoars: A literature review and report of a case. Ann Pharmacother 1998;32:940-6.

6. Kadian RS, Rose JF, Mann NS. Gastric bezoars - Spontaneous resolution. Am J Gastroenterol 1978;70:79-82.

7. Buckley NA, Dawson AH, Reith DA. Controlled release drugs in overdose. Clinical considerations. Drug Saf 1995;12:73-84.

8. Stack PE, Thomas E. Pharmacobezoar: An evolving new entity. Dig Dis 1995;13:356-64.

9. Höjer J, Personne M. Endoscopic removal of slow release clomipramine bezoars in two cases of acute poisoning. Clin Toxicol (Phila) 2008;46:317-9.

10. Lapostolle F, Finot MA, Adnet F, Borron SW, Baud FJ, Bismuth C. Radiopacity of clomipramine conglomerations and unsuccessful endoscopy: Report of 4 cases. J Toxicol Clin Toxicol 2000;38:477-82. 